\title{
REFLEXÕES INTRODUTÓRIAS SOBRE A CRÍTICA DO PAPEL DA EDUCAÇÃO AMBIENTAL NA BUSCA PELO DESENVOLVIMENTO SUSTENTÁVEL
}

\section{INTRODUCTORY REFLECTIONS ABOUT THE CRITICAL ROLE OF ENVIRONMENTAL EDUCATION IN SEARCH FOR SUSTAINABLE DEVELOPMENT}

\author{
Jean Filippe Gomes Ribeiro \\ Universidade Estadual do Ceará \\ E-mail: jeanfillipeg@yahoo.com.br
}

\section{Resumo}

Esta pesquisa trata de uma reflexão introdutória e crítica à Educação Ambiental em busca do desenvolvimento sustentável, que se tornou um objeto de interesse de estudo para toda a sociedade e academia. No entanto existem dilemas e sérias críticas em relação à implementação de políticas públicas e na avaliação de experiências sustentáveis em todo o mundo. A proposta deste artigo é discutir de maneira introdutória uma análise sobre a forma como se dá a implementação e a preocupação do meio ambiente, por meio de política desenvolvimento sustentável se utilizando da Educação como forma de conscientização. Assim se faz necessário avaliar discurso sobre o tema.

Palavras-chave: educação ambiental. sustentabilidade. políticas públicas.

\begin{abstract}
This research is about an introductory reflection and criticism related to environmental education towards sustainable development has become an object of study of interest to society and academy. However there are dilemmas and serious criticism of the implementation of public policies and the evaluation of sustainable experiences all over the world. The purpose of this article is to discuss the way introductory analysis on how it is placed and the environmental concern through sustainable development policy of using education as a form of awareness, so it is necessary to evaluate speech on the topic.
\end{abstract}

Keywords: environmental educational. sustainability. public policies. 


\section{INTRODUÇÃO}

O tema deste trabalho é a Educação Ambiental (EA), um assunto que vêm ganhando cada vez mais popularidade e aplicabilidade dentro da Educação em todo o mundo, pois se propõe a ser uma prática social para contornar os problemas que a sociedade do consumo trouxe para sociedade. Desta forma, políticas públicas foram adotadas para respaldar este ensino juntamente com o conceito de desenvolvimento sustentável em nossa sociedade.

Esta pesquisa é sobre um breve resgate conceitual e histórico do que seria a Educação Ambiental e o desenvolvimento sustentável, realizando uma crítica do seu uso como forma de "salvação da sociedade" diante dos problemas ambientais que estão postos na sociedade moderna. Demonstrando assim, que existem muitos outros agentes que contribuem para os problemas ambientais, mais do que a sociedade civil.

\section{DA CRISE ECOLÓGICA À EDUCAÇÃO AMBIENTAL}

Uma questão a ser colocada é que a crise ambiental não é algo ligado apenas ao meio ambiente, mas, sim, a toda uma conjuntura política e de consumo desenfreado. Sendo assim, a crise é resultado de ações maléficas que homem vem realizando sobre meio ambiente; e isto não vem de hoje, mas desde o período da Idade Média. Na contemporaneidade, a crise se reflete em várias esferas de atuação humana, e sempre em busca de desenvolvimento a qualquer preço. Daí a ironia de se pensar agora em desenvolvimento que seja sustentável.

E assim, entre as nações, cresce cada vez mais o medo de catástrofes causadas pelo desequilíbrio ambiental e o esgotamento dos recursos naturais. Por isso existe um aumento da busca por soluções que minimizem estes impactos, como é a proposta da Educação Ambiental.

O debate sobre a relação entre educação e meio ambiente se desenvolve no contexto de problematização da própria crise ambiental e se institucionaliza através da iniciativa da Organização das Nações Unidas - ONU, e de seus países membros, que promoveram os primeiros encontros internacionais para discutir, estabelecer diretrizes, normas e objetivos para o problema (LIMA, 1999 p.03).

O conceito de Educação Ambiental aparece pela primeira vez à expressão "environmental 
education" em 1965, na Grã-Bretanha, na Conferência em Educação, realizada em Keele,aonde se chegou à conclusão de que a Educação Ambiental necessitaria se tornar parte essencial da educação de todos os cidadãos (DIAS, 1992, p. 35). Posteriormente, em 1970, os Estados Unidos aprovaram a primeira lei sobre Educação Ambiental. Mais tarde a EA se tornará um conceito universal pelo Programa Internacional de Educação Ambiental (PIEA). Um de seus objetivos foi uma introduzir na política internacional as preocupações ambientais, propondo medidas que de alguma forma limitassem o modelo tradicional de crescimento econômico e o uso desenfreado dos recursos naturais.

A prática da Educação Ambiental consiste em levar o homem a viver em harmonia com a natureza por meio da participação de todos os cidadãos na solução dos problemas e preocupações ambientais. Podemos dizer que o seu intuito surgiu da vontade de conscientizar cada vez mais e mudar os comportamentos humanos, frente às características dos espaços naturais e modificados, fazendo com que os mesmo fossem restaurados e trazendo consigo um equilíbrio entre homem e natureza.

A EA, segundo Carvalho (2001), se divide em dois grandes grupos que possuem práticas diferentes e podem ser classificadas em EA comportamental e EA popular.

Com o debate ambientalista generaliza-se um certo consenso no plano da opinião pública, a respeito da urgência de conscientizar os diferentes estratos da população sobre os problemas ambientais que ameaçam a vida no planeta. Consequentemente, é valorizado o papel da educação como agente difusora dos conhecimentos sobre o meio ambiente e indutor da mudança dos hábitos e comportamentos considerados predatórios, em hábitos comportamentos tidos como compatíveis com a preservação dos recursos naturais. Uma outra ideia bastante recorrente nesta perspectiva é a de que, embora todos os grupo sociais devam ser educados para a conservação ambiental, as crianças são um grupo prioritário. As crianças representam aqui as gerações futuras em formação [...] $(2001$, p.46).

Enquanto que a Educação Ambiental popular seria:

Esta EA está associada com a tradição da educação popular que compreende o processo educativo como um ato político no sentido amplo, isto é, como prática social de 
formação de cidadania. A EA popular compartilha com essa visão a ideia de que a vocação da educação é a formação de sujeitos políticos, capazes de agir criticamente na sociedade. O destinatário desta educação são os sujeitos históricos, inseridos numa conjuntura sociopolítica determinada, cuja ação, sempre intrinsecamente política, resulta de um universo de valores construído social e historicamente. Nesta perspectiva, não se apaga a dimensão individual e subjetiva, mas esta é vista desde sua intersessão com a cultura e a história, ou seja, o indivíduo é sempre um ser social. [...] Assim, o foco de uma EA popular não são exclusivamente os comportamentos [...] principalmente no conceito de conscientização [...] (CARVALHO, 2001, p.46-47).

Uma questão muito discutida dentro da EA é que a mesma não deve ser vista como apenas uma forma de educacional e não como um ato político: ela é uma forma de exercitar a cidadania dos indivíduos em sociedade, em que a sua formação depende da sua construção social e de seus valores adquiridos e difundidos. A EA não é uma forma apenas de se preservar o verde, mas de se ter uma consciência sobre o tema.

O surgimento e desenvolvimento da Educação Embiental como método de ensino estão diretamente relacionados ao movimento ambientalista, pois é fruto da conscientização da problemática ambiental. A ecologia como ciência global trouxe a preocupação com os problemas ambientais, surgindo a necessidade de se educar no sentido de preservar o meio ambiente.

Desta forma, a importância de Educação Ambiental está à noção de Desenvolvimento Sustentável, de acordo com a declaração colocada no Relatório "O Nosso Futuro Comum", apresentado em 1987. Por desenvolvimento sustentável entende-se "aquele que atende às necessidades do presente sem comprometer a possibilidade de as gerações futuras atenderem às suas próprias necessidades" (Gro Brundtland, primeira ministra da Noruega e presidente da Comissão Mundial para o Ambiente e Desenvolvimento).

Diante de vários conceitos que a EA pode assumir, temos de pensar primeiramente que tal educação não é uma prática desvinculado da realidade e das práticas social, mas, sim, imersa na conjuntura. 


\section{AS AÇÕES DE POLÍTICAS PÚBLICAS NO ÂMBITO DA SUSTENTABILIDADE}

A ideia de sustentabilidade que surgiu na metade dos anos 70 é um conceito de ligado a discurso de desenvolvimento sustentável nascido no âmbito da Ecologia que começou a ser discutido no meio científico e por ambientalistas. Foi usado oficialmente pela primeira vez na Assembleia Geral das Nações Unidas, em 1979, popularizando-se somente nas décadas seguintes, devido os problemas sociais e a escassez de recursos naturais causadas pelo modelo econômico adotado pelo homem.

Foi um evento onde as nações do mundo se reuniram e discutiram medidas que buscavam a preocupação com o meio ambiente e ações em prol ao desenvolvimento sustentável.

Neste evento foi proposto um documento chamado Agenda 21, que endossava os conceitos ligados ao tema desenvolvimento sustentável.

A Agenda 21 é um documento com 40 capítulos criado após a Conferência das Nações Unidas sobre Meio Ambiente e Desenvolvimento (CNUMAD), mais conhecida como o ECO-92 ou Rio 92 ocorrida no Rio de Janeiro, em 1992. Tal documento foi uma ideia conjunta dos cerca de 179 países envolvidos na conferência, que tiveram como propósito rumar ao progresso econômico e material com uma consciência ecológica. Suas diretrizes promovem a importância de cada país signatário se comprometer a refletir, global e localmente, sobre a forma como governos, empresas, organizações não-governamentais e demais os setores da sociedade poderiam cooperar no estudo de soluções para os problemas sócio-ambientais, estabelecendo um novo padrão de desenvolvimento de proteção ambiental, justiça social e eficiência econômica.

Cada país desenvolve a sua Agenda 21 e no Brasil as discussões são coordenadas pela Comissão de Políticas de Desenvolvimento Sustentável e da Agenda 21 Nacional (CPDS). Além da Agenda 21, este evento ainda resultou mais cinco outros acordos: a Declaração do Rio, a Declaração de Princípios sobre o Uso das Florestas, o Convênio sobre a Diversidade Biológica e a Convenção sobre Mudanças Climáticas.

A proposta da Agenda 21 foi construir um programa dinâmico com bases em um plano de ação e 
de planejamento participativo em âmbito global, nacional e local, de forma gradual e negociada. No Brasil os programas de inclusão social (com o acesso de toda a população à Educação, Saúde e distribuição de renda), além da sustentabilidade urbana e rural e da preservação dos recursos naturais e minerais, compõem nossa ética política, que orienta a busca por solucionar os problemas ambientais mundiais e acelerar o desenvolvimento sustentável. Um ponto importante dessas ações prioritárias é o planejamento de sistemas de produção e consumo sustentáveis contra a cultura do desperdício seja pelo governo o pela sociedade civil. Além do mais ampla participação pública e o envolvimento ativo das organizações não-governamentais e de outros grupos também devem ser estimulados.

\section{EDUCAÇÃO E REPRODUÇÃO SOCIAL: DEBATES SOBRE A SUSTENTABILIDADE}

Dentre as diversas concepções de princípios e práticas da EA, diversos autores como Layrargues (2006), Lima (1999) e Loureiro (2006) destacam alguns aspetos do papel que a Educação Ambiental representa dentro do contexto social.

Primeiramente cabe destaque à excessiva ênfase dada aos aspectos técnicos e biológicos da questão ambiental. Em algumas práticas que são concebidas dentro do âmbito da EA, demoradamente se dá destaque a explicações de fenômenos naturais e a viabilidade técnica da solução de problemas rumo à sustentabilidade. Tal postura deixa de lado as dimensões políticas da questão ambiental.

Para além de uma postura ingênua ou simplesmente um erro metodológico, esta postura carrega consigo um aspecto fundamental de como é concebida e praticada a EA: ao se deslocar do plano político para as feições técnicas ou meramente físico-biológicas, deixa-se de questionar quais os aspectos das relações sociais estão ligados à crise ambiental, que passa a ser encarada como um evento sem história e sem sujeito para o qual uma mudança cultural se faz necessária na adoção de novas práticas e tecnologias.

Assim as bases sociais da origem da crise ambiental não são questionadas e a Educação Ambiental, sob a égide da mudança cultural ou comportamental, cumpriu o papel de ocultar e reproduzir as bases sobre as quais se dão as relações sociedade-natureza no momento histórico em que 
perpassa pela crise ambiental; daí a crítica ao conceito de desenvolvimento sustentável, tão almejado pela EA, que, embora se coloque como uma nova forma de desenvolvimento, não modifica o sentido de dominação econômica na ordem internacional (LIMA, 1999).

Outro desdobramento desta postura é que, sem uma crítica dos fatos sociais e políticos da questão ambiental, muitas das práticas adotadas pela EA fixam-se na mudança de comportamentos individuais com base em uma "ética ambiental" que visa dar solução aos problemas da relação "Homem-Natureza". Desta forma a coleta seletiva, o consumo sustentável e os mutirões de limpeza, por exemplo, são vistos como posturas essenciais do indivíduo para outra relação com a natureza e acredita-se que a soma das posturas ecologicamente "corretas" levaria a tais relações. Esquece-se que

não há ação educativa sem atitudes individuais coerentes e sinceras. Contudo, destacamos que essa transformação do "eu" é mediatizada pela sociedade [...] e pelas relações com "outro". Assim é preciso que se entenda a complexidade do processo de transformação global a que se dispõe a educação ambiental (LOUREIRO, 2002 p.20)

Como evidenciado, a simples assimilação de "novas posturas", deslocadas de uma crítica do seu contexto social, político e histórico representados pelo padrão de produção e consumo em nossa sociedade, nos aproxima muito mais das condições sociais e históricas que deram origem à crise ambiental do que a uma ruptura no sentido de transformação desta realidade. Para Layrargues (2006),

a educação ambiental, antes de tudo, é Educação, esse é um pressuposto inquestionável. Nesse sentido, nenhuma discussão a respeito das metas, objetivos e avaliação da educação ambiental que mereça credibilidade pode deixar de abordar a perspectiva sociológica da Educação como um instrumento ideológico de reprodução das condições sociais (p.05).

Assim sem uma análise que leve em consideração não a apenas a importância da educação ambiental, qual seja o próprio processo educativo sobre o prisma da relação sociedade- natureza, mas o papel que ela desempenha socialmente conduz a uma postura sem um posicionamento 
crítico da educação ambiental enquanto processo educativo e as suas práticas a uma remodelação das relações sociais excludentes vigentes.

Entendida desta maneira, o papel que a Educação Ambiental cumpre como indutora de uma mudança cultural, perpassada por um debate ético que visa corrigir o afastamento do homem da natureza, enquanto fundamento da crise ambiental (LAYRARGUES, 2006), não está dissociado da concepção de educação ambiental somente enquanto instrumento de socialização humana, ocultando seu papel como instrumento de reprodução das condições sociais. Afinal, enquanto processo social, a educação está permeada por concepções ideológicas, políticas e de poder.

Em uma sociedade de classes a educação tem a função primordial de reproduzir as relações hegemônicas estabelecidas, naturalizar a forma como a sociedade é reproduzida em suas mais agudas contradições, sempre a serviço das classes dominantes. É desta forma que o debate sobre a sustentabilidade emerge dentro da educação ambiental e se propaga pelos meios de comunicação:

A ideia desenvolvimento sustentável retoma outra ideia de que os problemas são ocasionados por desvios do modelo e que é possível corrigi-los comum planejamento que pode ocorrer nos tratados internacionais [...] assim cria-se e/ou recria-se uma cortina de fumaça sobre a dilapidação do ambiente, as contradições e os conflitos de classe e de apropriação do território (RODRIGUES, 2009 p.188)

O planejamento, a tecnologia e a mudança comportamental são vistos como os horizontes para uma nova era de relacionamento com a natureza, no entanto escamoteia-se que tais "alternativas" tragam embutidas em si a própria sociedade que as criou e suas contradições na dilapidação dos recursos naturais e na sua desigual apropriação bem como dos danos ambientais.

A partir desta reflexão faz-se imprescindível entender a papel político desempenhado pela educação (ambiental) e sobre as posturas reflexões que ela propõe. O senso comum está permeado por uma série de imprecisões e reproduções desta forma de pensar e agir. Os meio de comunicação cumprem importante tarefa na mistificação destas concepções, ao mesmo tempo em que impõe a disseminações de conceitos vagos tanto em sua elaboração teórica como prática. 
A busca por um processo educativo que também seja ambiental deve se pautar na crítica da sociedade existente e suas estratégias de reprodução. Propostas de alternativas ao atual modelo devem ser observadas sob o prisma das contradições existentes na sociedade. Desta maneira, as relações sociais deixam de ser abstratas e torna-se possível identificar os principais conflitos existentes; e é sobre estes que a educação ambiental deve atuar, de modo que educadores e educandos possam elaborar propostas de intervenção sobre uma base concreta de relações entre a natureza e a sociedade.

\section{CONSIDERAÇÕES FINAIS}

O discurso em torno das questões ambientais que se tornou amplamente debatido na esfera pública, privada, acadêmica e pelos meios de comunicação, que apontam para o desenvolvimento de uma consciência ambiental e sustentável que baseiam a criação de políticas e posturas como a Agenda 21 e as políticas de educação ambiental. A Educação Ambiental ganha bastante destaque por se colocar como um processo capaz de orientar novos comportamentos para a superação da atual relação entre a sociedade e a natureza. Sob esta perspectiva são elaboradas diversas práticas, muitas das quais com um caráter enfático a questões físico-biológicas.

O desenvolvimento sustentável colocado como a possibilidade de um novo modelo de organização social, baseado na utilização racional dos recursos e na sua preservação para as gerações posteriores, é visto como alternativa e a EA cumpriria, assim, a função de disseminar as posturas necessárias, para tal fim, calcadas numa nova "ética" da relação sociedade-natureza.

A concepção de EA sem um debate crítico sobre o papel que ela desempenha enquanto processo educativo (não simplesmente como um instrumento de socialização humana, mas de reprodução das condições sociais existentes) é forma predominante adotada, o que leva a práticas e posturas socialmente abstratas que não revelam a essência da crise ambiental.

Assim faz-se primordial para o desenvolvimento de um processo educativo que também é ambiental) capaz de compreender as contradições existentes nas relações sociais a adoção de uma postura crítica que visualize a sociedade com um produto de relações sociais permeadas de concepções políticas, ideologias e poder. Contribuindo assim para que o debate em torno da 
questão ambiental se coloque de forma a romper a forma desigual de dilapidação dos recursos naturais e de apropriação de riquezas.

\section{REFERÊNCIAS}

CARVALHO, Isabel Cristina de Moura. Qual educação ambiental? Elementos para um debate sobre educação ambiental e extensão rural. Disponível em: $<$ http://www.agroecologia.inf.br/biblioteca/educacao\%20ambiental.pdf $>$. Acesso 1 de abril de 2011.

CARVALHO, I.C.M. Educação, meio ambiente e ação política. In: ACSELRAD, H. (Org). Meio ambiente e democracia. Rio de Janeiro, IBASE, 1992.

FERREIRA, L. C. Cidades, sustentabilidade e risco. Revista Desenvolvimento e Meio Ambiente, Curitiba, Editora da UFPR, n.9, p.23-31, 2004.

GIANSANTI, Roberto. O desafio do desenvolvimento sustentável, São Paulo, Atual, 1998.

GRYZINSKI, Vilma. Perigo real e imediato. Veja, edição 1926, ano 38, no 41, p. 84-87, 12 de out. 2005.

LIMA, Gustavo Ferreira da Costa. Questão ambiental e educação: Contribuições para o debate. NEPAM/UNICAMP, Campinas, ano II, no 5,1999.

LOREIRO, C. F. B. Trajetórias e fundamentos da educação ambiental. São Paulo: Cortez, 2006.

LOUREIRO, C.F.B.; LAYRARGUES, P.P.; CASTRO, R.C. de (orgs.). Pensamento complexo, dialética e educação ambiental. São Paulo: Cortez, 2006.

RODRIGUES, A. M. A abordagem ambiental: questões para reflexão. GeoTextos, Salvador, vol. 5 no 10 jul 2009. P. 183-201.

TAVARES, Everkley Magno Freire. Avaliação de políticas públicas de desenvolvimento sustentável: dilemas teóricos e pragmáticos. Disponível em: <http://www2.ifrn.edu.br/ojs/index.php/HOLOS/article/viewFile/63/69>. Acesso em: $30 \mathrm{mar}$ 2001.

ECOL NEWS. Agenda 21. Disponível em: <http://www.ecolnews.com.br/agenda21/>. Acesso em 2 de abril de 2011. 